\section{Subjective contours and apparent depth: A direct test}

\author{
STANLEY COREN \\ University of British Columbia \\ Vancouver, British Columbia, Canada
}

and

\author{
CLARE PORAC \\ University of Victoria \\ Victoria, British Columbia, Canada
}
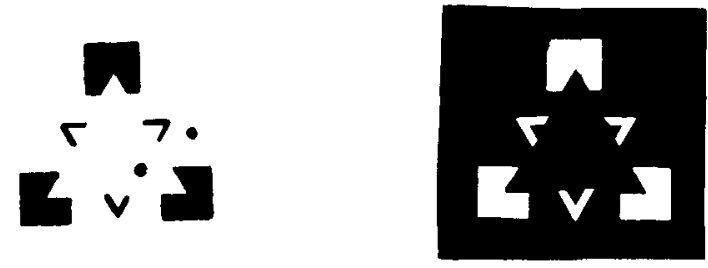

A
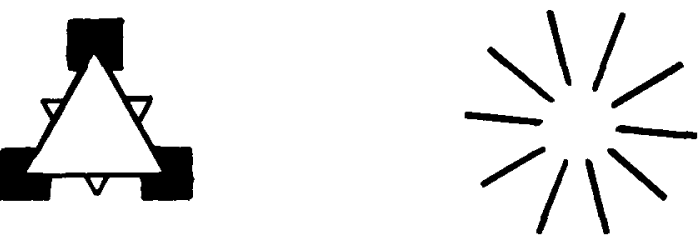

which show subjectively contoured white and black triangles, respectively, and in Figure 1D, which shows a subjectively contoured white circle. These subjective contours are associated with some additional perceptual effects. Typically, observers report that the figures bounded by subjective contours appear lighter or darker than the surfaces upon which they rest, and also that they appear to stand out in front of the background (see Coren, 1972, and Kanizsa, 1955).

Many hypotheses have been offered to explain the existence of subjective contours. Several of these involve purely physiological mechanisms, such as those of Brigner and Gallagher (1974), Day and Jory (1978, 1980), Frisby and Clatsworthy (1975), and Jory and Day (1979), who contend that subjective contours are formed as a secondary consequence of brightness contrast. There are, however, some difficulties with such contrast explanations, since equivalent objectively contoured figures are not associated with the same brightness effects (Coren \& Theodor, 1975). Alternative physiological explanations are based on contour-specific neural receptors in the cortex and suggest that the inducing elements evoke activity in neural units that would normally respond to an edge at that locus in space (Smith \& Over, 1975, 1979), or are based on Fourier analysis processes in the visual system (Ginsburg, 1975). None of these processes,

We would like to thank Miriam Blum for her assistance in data collection. This research was supported by grants from the Natural Sciences and Engineering Research Council of Canada and represents an equal and shared contribution of both authors. S. Coren's mailing address is: Department of Psychology, University of British Columbia, Vancouver, British Columbia V6T IW5, Canada. C. Porac's mailing address is: Department of Psychology, University of Victoria, Victoria, British Columbia V8W 2Y2, Canada.
Figure 1. Stimulus patterns used in this experiment. (A and B) Subjective-contour triangle patterns (after Coren, 1972). (C) Objective-contour control array (after Porac, 1978). (D) Subjective-contour circle (after Kennedy, 1978). Spots on Pattern A mark the approximate location of the figare and background target locations.

however, explains such secondary effects associated with subjective contours as changes in brightness or in apparent depth.

In contradistinction to the physiological explanations are a number of hypotheses that are primarily cognitive in nature. Kanizsa (1976) maintains that illusory contours are merely an unusually strong example of the Gestalt principle of closure. Other theorists suggest, rather, that subjective contours emerge as some form of unconscious inference on the partial figural cues present in the inducing array, in much the same way as meaning is abstracted from incomplete outline drawings or cartoons (Bradley \& Dumais, 1975; Gregory, 1972; Kennedy, 1976; Piggins, 1975; Rock and Anson, 1979).

Coren (1972) has offered an alternative cognitive theory. He suggested that subjective contours result from the organization of the percept around implicit depth cues in the two-dimensional array, and offered demonstrations of the creation of subjective contours by the manipulation of depth cues. Halpern (1981) showed a manifest depth component by having subjects reproduce the apparent depth separation between a subjective contour and its background on a two-dimensional horizontal line. In indirect tests, 
Coren (1972) and Porac (1978) have shown that size constancy scaling can be triggered by the apparent depth in subjective contours. Somewhat more direct tests have involved actual manipulation of depth cues. Gregory and Harris (1974), Lawson, Cowan, Gibbs, and Whitmore (1974), and Whitmore, Lawson, and Kozora (1976) presented subjective-contour figures stereoscopically and showed that, when the binocular disparity cues were in opposition to the implicit depth cues, the subjective contours disappeared, results they interpreted as supporting the depth-cue hypothesis.

The above results certainly suggested that segregation of the array into apparent depth was an integral part of the perception of subjective contours. However, we believed a stronger case for, or against, the apparent-depth hypothesis would be provided by a direct depth-measuring technique involving a visual nulling or visual ranging procedure, and the following experiment was therefore performed.

\section{METHOD}

\section{Stimuli and Apparatus}

The apparatus was similar to that employed by other investigators who have attempted direct measurements to assess apparent depth (Coren \& Festinger, 1967; Gregory, 1966; Kilbride \& Leibowitz, 1975). The general method is to superimpose a binocularly viewed target on a monocularly viewed stimulus pattern whose depth characteristics one wants to assess. The binocular target can be imaged directly over any component of the figure in order to measure its apparent depth. The observer adjusts the binocular spot (which appears to vary in distance as a function of binocular disparity) until it appears to be positioned at the same phenomenal depth as the portion of the stimulus array upon which it is imaged.

Each stimulus was prepared as a slide and projected upon a rear-projection screen. Mounted in front of the screen was a sheet of polarizing material. The image of the adjustable depth spot was reflected to the observer's eyes by means of a half-silvered mirror, through which the polarized monocular stimulus pattern was also visible. A pair of orthogonally oriented Polaroid filters was placed in the viewing port. These allowed the subjective-contour-inducing stimuli to be seen by only one eye, while the spot (provided by a red-filtered grain-of-wheat bulb) was seen by both eyes. The observer varied the apparent distance of the binocular spot by adjusting its position laterally along an optical bench rail. The position of the spot provided the measurement of apparent depth directly in millimeters.

The subjective-contour stimuli used in this study are shown in Figure 1. Figures $1 A$ and 1B.were taken from Coren (1972). Figure $1 \mathrm{~A}$, a white subjective triangle lies against a white background; Figure $1 B$ is a reversed brightness variant, in which a black subjective contour is seen against a black background. Figure $1 \mathrm{C}$ is a control configuration with real contours, adapted from Porac (1978). Figure 1D, a white disk against a starburst pattern of black lines, is adapted from Kennedy (1978). The size of the sides of the stimulus triangles in Figures 1A, 1B, and 1C was 7 deg of arc, which was also the diameter of the stimulus circle in Figure 1D. The overall field size was a 20-deg square. The binocular adjustable point was $10 \mathrm{sec}$ of arc when measured at the same apparent distance as the subjective-contour portion of the stimulus patterns. The luminance at the viewing port was $40 \mathrm{~cd} / \mathrm{m}^{2}$ for the white regions of the stimulus, $.5 \mathrm{~cd} / \mathrm{m}^{2}$ for the black regions of the field, and $32 \mathrm{~cd} / \mathrm{m}^{2}$ for the adjustable red stimulus spot.

\section{Subjects and Procedure}

Twenty observers were paid for their participation in this experiment. Each had visual acuity of $20 / 25$ or better in each eye and normal stereopsis when tested with a Keystone telebinocular. All were naive about the existence of subjective contours and about the nature of the stimulus presentation.

To ascertain the apparent distance of the subjective-contour figure relative to its background, the adjustable test target was superimposed on the region of the array that the observer was to judge. To assess the apparent depth in the stimulus, the spot was imaged on the figure, $1 \mathrm{deg}$ to the inside of the apparent subjective contour or $1 \mathrm{deg}$ to the outside of the subjective contour (approximate positions are marked as spots on Figure 1A). The same relative placements were used for the real-contour control (Figure 1C) and the starburst (Figure 1D).

Every observer was tested on all stimuli and both test placements. Stimulus patterns were presented in random order, and the binocular spot placement was also determined randomly. The observer was required to make two settings on each trial, from randomly determined apparent near and far starting points, in counterbalanced order. The observer was instructed to place the binocular adjustable target so that it appeared to be at the same distance from them as the part of the stimulus (figure or background) upon which it was superimposed. Every observer participated in two measurement blocks, each consisting of all stimulus and spot placement combinations. There was a brief rest period between testing blocks.

\section{RESULTS AND DISCUSSION}

The four settings for each configuration and spot placement were averaged for each observer. These results appear in Table 1 (configurations are identified by the same letters as are used in Figure 1).

The measurements indicate that, for each of the four patterns, the part of the field identified as the figure is seen as nearer to the observer than the part of the field seen as the background. This is true for the objective contour (Figure 1C) and for the subjective contours (Figures 1A, 1B, 1D). An analysis of variance showed that this effect is statistically significant $[F(1,19)=19.28, p<.001]$. Individual $t$ tests further confirmed this result for each stimulus separately, by showing that, for each of the four configurations, the binocular measurement spot was set closer to the observer when it was superimposed upon the figure than when it was placed upon the background ( $p<.01$ for all four pairings).

The four configurations differ significantly, however, in the amount of manifest depth, indicated by the difference between depth settings for figure and background. An analysis of variance of these differ-

Table 1

Settings of Apparent Distance (in Centimeters) From the Observer for Figure and Background for the Four Stimulus Configurations Labeled as in Figure 1

\begin{tabular}{lcccc}
\hline & \multicolumn{4}{c}{ Stimulus Configuration } \\
\cline { 2 - 5 } Target & $\mathrm{A}$ & $\mathrm{B}$ & $\mathrm{C}$ & $\mathrm{D}$ \\
\hline Focation & 31.1 & 30.9 & 35.1 & 31.9 \\
Backure & 42.3 & 42.0 & 40.6 & 37.8 \\
\hline
\end{tabular}


ence scores showed that the magnitude of the depth differences varied across the four patterns $[F(3,57)$ $=4.412, \mathrm{p}<.01]$. Contrast analyses indicated no significant difference between the black and the white triangle configurations; (mean depth effect $=11.2 \mathrm{~cm}$ ); however, both showed a significantly greater depth effect than that found in the objective contour and the radiating line configurations (mean depth effect $=5.7 \mathrm{~cm}$ ).

The differential ability of the various configurations to produce segregation of figure and background into different depth planes is interesting. The finding that the real-contour control configuration (Figure 1C) shows some depth segregation verifies Porac's (1978) observations; however, the depth difference appears to be attenuated relative to the subjectively contoured figures. The appearance of depth segregation in the starburst (Figure 1D) is of particular theoretical relevance. Kennedy (1976) demonstrated that some subjective-contour-inducing stimuli can be constructed from such arrays of lines even if the implicit depth cues are labile or ambiguous, as here. This led him to doubt the necessity of depth segregation as a component in the formation of subjective contours. The present results indicate that, although such arrays produce less pronounced effects, apparent depth is present in the final percept.

The present results are consistent with Coren's (1972) hypothesis that subjective contours are associated with implicit depth cues in an array. The two configurations that form the strongest subjective contours in this stimulus set (Figures 1A and 1B) also produce the most pronounced apparent-depth difference. These results emerge from the direct measurement of apparent depth and confirm the role of depth processing in the formation of subjective contours, previously indicated by indirect measures. However, we must note that these observations support only a covariation between depth processing and subjective contours, which does not necessarily require a causal mechanism such as Coren originally hypothesized. Perhaps apparent depth emerges in subjective-contour configurations as a secondary consequence of the formation of the illusory contour itself, the contour itself being initially evoked by some other mechanism. Alternatively, it may be a multicausal system with organization around implicit depth cues as one aspect of the process. Such multicausality has been suggested for a number of illusory percepts (Coren \& Girgus, 1978; Coren, Girgus, Erlichman, \& Hakstian, 1976; Coren \& Porac, 1979; Coren \& Ward, 1979; Porac \& Coren, 1981) and has been suggested recently for subjective-contour arrays (Halpern, 1981). In any event, these results clearly confirm the contention that stratification into several levels of depth seems to be a common feature of subjective-contour configurations.

\section{REFERENCES}

Bradefy, D. R., \& Dumais, S. F. Ambiguous cognitive contours. Nature, 1975, 257, 582-584.

Bhigner, W. L., \& Gallagher, M. B. Subjective contour: Apparent depth through simultaneous contrast? Perceptual and Motor Skills, 1974, 38, 1047-1053.

Coren, S. Subjective contours and apparent depth. Psychological Review, 1972, 79, 359-367.

Coren, S., \& Festinger, L. An alternative view of the "Gibson normalization effect." Perception \& Psychophysics, 1967, 2, 621-626.

Coren, S., \& Girgus, J. S. Seeing is deceiving: The psychology of visual illusions. Hillsdale, N.J: Erlbaum, 1978.

Coren, S., Girous, J. S., Erlichman, H., \& Hakgtian, A. R. An empirical taxonomy of visual illusions. Perception \& Psychophysics, 1976, 20, 129-137.

Coren, S., \& Ponac, C. Heritability in visual-geometric illusions: A family study. Perception, 1979, 8, 303-309.

Coren, S., \& Theodor, L. H. Subjective contour: The inadequacy of brightness contrast as an explanation. Bulletin of the Psychonomic Society, 1975, 6, 87-89.

COREN, S., \& WARD, L. M. Levels of processing in visual illusions: The combination and interaction of distortion-producing mechanisms. Journal of Experimental Psychology: Human Perception and Performance, 1979, 5, 324-335.

DAY, R. H., \& JoRY, M. K. Subjective contours, visual acuity, and line contrast. In J. C. Arington, J. Krauskopf, \& B. R. Wooten (Eds.), Visual psychophysics and physiology: $A$ volume dedicated to Lorin Riggs. New York: Academic Press, 1978.

DAY, R. H., \& JoRY, M. K. A note on the second stage of the formation of illusory contours. Perception \& Psychophysics, $1980,27,89-91$.

Frisay, J. P., \& Clatsworthy, J. L. Illusory contours: Curious cases of simultaneous brightness contrast? Perception, 1975, 4, 349-357.

Ginsburg, A. P. Is the illusory triangle physical or imaginary? Nature, 1975, 257, 219-220.

Greoory, R. L. Visual illusions. In B. Foss (Ed.), New horizons in psychology. Baltimore: Penguin Books, 1966.

GRE GORY, R. L. Cognitive contours. Nature, 1972, 238, 51-52.

Gregory, R. L., \& Harris, J. B. Illusory contours and stereo depth. Perception \& Psychophysics, 1974, 15, 411-416.

HALPERN, D. F. The determinants of illusory-contour perception. Perception, 1981, 10, 191-213.

JORY, M., \& DAY, R. The relationship between brightness contrast and illusory contours. Perception, 1979, 8, 3-9.

Kanizsa, G. Marzini quasi-perceptivi in campi con stimolazione omegenea. Revista di Psicologia, 1955, 49, 7-30.

KanizsA, G. Subjective contours. Scientific American, 1976, 234, 8-52.

KENNEDY, J. M. Attention brightness in the constructive eye. In M. Henle (Ed.), Vision and artifact. New York: Springer, 1976.

KenNedy, J. M. Illusory contours in the ends of lines. Perception, 1978, 7, 605-607.

Kilbride, P. L., \& Leibowitz, H. W. Factors affecting the magnitude of the Ponzo illusion among the Baganda. Perception Psychophysics, 1975, 17, 543-548.

Lawson, R. B., Cowan, E., Gibgs, T. D., \& Whitmone, C. T. Stereoscopic enhancement and a ratio of subjective contours. Journal of Experimental Psychology, 1974, 103, 1142-1146.

Pigoins, D. J. Cognitive space. Perception, 1975, 4, 337-340.

Porac, C. Depth in objective and subjective contour patterns. Bulletin of the Psychonomic Society, 1978, 11, 103-105.

Porac, C., \& Coren, S. Life-span age trends in the perception of the Mueller-Lyer: Additional evidence for the existence of two illusions. Canadian Journal of Psychology, 1981, 35, 58-62. 
Rock, I., \& Anson, R. Illusory contours as the solution to a problem. Perception, 1979, 8, 665-681.

Smith, A., \& Over, R. Tilt after-effects with subjective contours. Nature, 1975, 257, 581-582.

Sмiтr, A., \& Over, R. Motion after-effect with subjective contours. Perception \& Psychophysics, 1979, 25, 95-98.
Whitmore, C. L. G., Lawson, R. B., \& Kozora, C. E. Subjective contours and stereoscopic space. Perception \& Psychophysics, 1976, 19, 211-213.

(Manuscript received May 10, 1982;

revision accepted for publication November 19,1982 .) 